\title{
Characterization of the pH-Dependent Resonance Raman Transitions of Archaeal and Bacterial Rieske [2Fe-2S] Proteins
}

\section{- Supporting Information -}

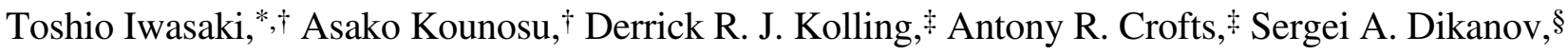 \\ Akihisa Jin,\| Takeo Imai,\|l and Akio Urushiyamall
}

Reference (18c) In contrast to the high-potential proteins, which exhibit a $5-\mathrm{cm}^{-1}$ upshift of the $270-\mathrm{cm}^{-1}$ band under alkaline conditions near and above $\mathrm{p} K_{a, o x 2}$, the low-potential ARF shows a substantial downshift of the $260-\mathrm{cm}^{-1}$ band as the breakdown process starts at $\mathrm{pH} 11.8$. These observations indicate that the $\mathrm{pH}$-dependent changes in vibrational modes (including this one) depend on the particular protein structure. The changes are consistent with reorganization of the polypeptide backbone structure around the [2Fe-2S] cluster, rather than simple changes of the $\mathrm{Fe}-\mathrm{N}_{\text {imid }}$ stretching vibrations, which would have brought a uniform shift of the RR band upon alkalization, independent of the protein structure.

Materials. Escherichia coli strain DH5 and strain HB101 (TaKaRa) used for cloning were grown in LB or TB medium, with $50 \mu \mathrm{g} / \mathrm{ml}$ ampicillin when required. Plasmids pGEMT and pGEM3Zf(+) (Promega) were used for cloning and sequencing. The expression vector pET28a was purchased from Novagen. Deuterium oxide $\left(\mathrm{D}_{2} \mathrm{O}\right)(99.9 \%$, NMR grade) was purchased from Wako Pure Chemicals (Osaka, Japan), and water was purified by a Milli-Q purification system (Millipore). Other chemicals mentioned in this study were of analytical grade.

Sample preparation. The $s d x$ gene coding for the high-potential, archaeal sulredoxin (SDX) (DDBJ accession number, AB023295) of S. tokodaii strain 7 (JCM 10545 ; formerly Sulfolobus sp. strain 7) ${ }^{1}$ and the arf gene coding for the low-potential, archaeal Rieske-type ferredoxin (ARF) (ORF c06009; DDBJ accession number AB047031) of S. solfataricus strain P-1 (DSM 1616 ${ }^{\mathrm{T}}$ ) have been cloned, sequenced, and heterologously overexpressed in E. coli as reported elsewhere. ${ }^{2,3}$

The pET28aSDX vector harboring the $s d x$ gene of $S$. tokodaii strain 7 and the pET28aARF vector harboring the arf gene of S. solfataricus strain P-1 were transformed separately into the host strain, E. coli 
BL21-CodonPlus(DE3)-RIL (Stratagene). The transformants were grown overnight at $25{ }^{\circ} \mathrm{C}$ in $\mathrm{LB}$ medium containing $50 \mu \mathrm{g} / \mathrm{ml}$ kanamycin, and the recombinant holoprotein was produced by induction with $1 \mathrm{mM}$ IPTG for $24 \mathrm{~h}$ at $25^{\circ} \mathrm{C}$ in the presence of $100 \mu \mathrm{M} \mathrm{FeCl}_{3}$. The cells were pelleted by centrifugation and stored at $-80{ }^{\circ} \mathrm{C}$ until use. Purification of the recombinant archaeal holoproteins having a His-tag at the N-terminus was performed as reported previously. ${ }^{2,4}$ When required, the recombinant archaeal holoprotein was further purified by a Sephadex G-50 gel filtration column (Amersham Pharmacia Biotech). The purified recombinant SDX and $\mathrm{ARF}$ were stored at either $-80{ }^{\circ} \mathrm{C}$ or $4{ }^{\circ} \mathrm{C}$ until use.

Rhodobacter sphaeroides cytochrome $b c_{1}$ complex was isolated and purified as previously reported..$^{5} \mathrm{~A}$ working concentration of $5.5 \mu \mathrm{M}$ thermolysin (Sigma Chemicals) was added to a solution of $50 \mu \mathrm{M}$ cytochrome $b c_{1}$ complex, $50 \mathrm{mM}$ 3-(N-morpholino) propanesulfonic acid (MOPS) buffer, $\mathrm{pH}$ 7.0, 100 $\mathrm{mM} \mathrm{NaCl}, 1 \mathrm{mM} \mathrm{MgSO} 4,0.01 \%$ (w/v) $n$-decyl- $\beta$-D-maltoside (Sigma Chemicals), $15 \mu \mathrm{g} / \mathrm{ml}$ phosphatidyl choline (Avanti Polar-Lipids, Inc., Alabaster, $\mathrm{AL}$ ), $10 \mathrm{mM} \mathrm{CaCl}$, and $100 \mu \mathrm{M}$ antimycin A. The reaction mixture was incubated at room temperature for $2.5 \mathrm{~h}$, at which time $15 \mathrm{mM}$ EDTA, $\mathrm{pH} 7.5$, was added to quench the digest. The reaction mixture was placed onto a hydroxyapatite column $(0.45 \mathrm{~g} / \mathrm{ml}$ reaction mixture, Aldrich) pre-equilibrated with $150 \mathrm{mM} \mathrm{NaCl}$ and $10 \mathrm{mM}$ potassium phosphate buffer, $\mathrm{pH}$ 7.2, at room temperature. The high-potential Rieske [2Fe-2S] cluster-binding domain fragment (ISP), which was solubilized by proteolytic cleavage from the hydrophobic $\mathrm{N}$-terminal tail, did not bind to the column, whereas unproteolyzed cytochrome $b c_{1}$ and other fragments bound tightly, allowing one to wash off the ISP with 2 to 3 column volumes. The sample was exchanged into $50 \mathrm{mM}$ Tris- $\mathrm{HCl}, \mathrm{pH} 9.0$, and further purified using a DEAE-Sephacel (Sigma) column with a salt gradient of 0 to $200 \mathrm{mM} \mathrm{NaCl}$ at $4{ }^{\circ} \mathrm{C}$.

Purified ISP, SDX, and ARF were each fully oxidized with a small amount of potassium ferricyanide solution and subjected to buffer exchange with a small Sephadex G-75 gel filtration column (Amersham Pharmacia Biotech) pre-equilibrated with $400 \mathrm{mM} \mathrm{NaCl}$ and $10 \mathrm{mM}$ Tris- $\mathrm{HCl}$ buffer, $\mathrm{pH}$ 7.5. For visiblenear UV circular dichroism (CD) measurement, each sample was concentrated with an Amicon Centriprep YM-10 (to 0.1-0.4 mM), mixed with an appropriate buffer, and measured for $\mathrm{pH}$ with a Horiba $\mathrm{pH}$ meter. For low-temperature resonance Raman (RR) measurement, each sample was concentrated with an Amicon Microcon YM-10 (to 1-4 mM), mixed with the same appropriate buffer used for CD measurement, and immediately further concentrated with an Amicon Microcon YM-10 (to 1-4 mM). $\mathrm{D}_{2} \mathrm{O}$ substitution was 
performed by exchanging the samples three times in potassium phosphate/ $\mathrm{D}_{2} \mathrm{O}$ buffer containing $400 \mathrm{mM}$ $\mathrm{NaCl}(\mathrm{pH}$ meter reading 6.9, uncorrected for deuterium) for $36 \mathrm{~h}$.
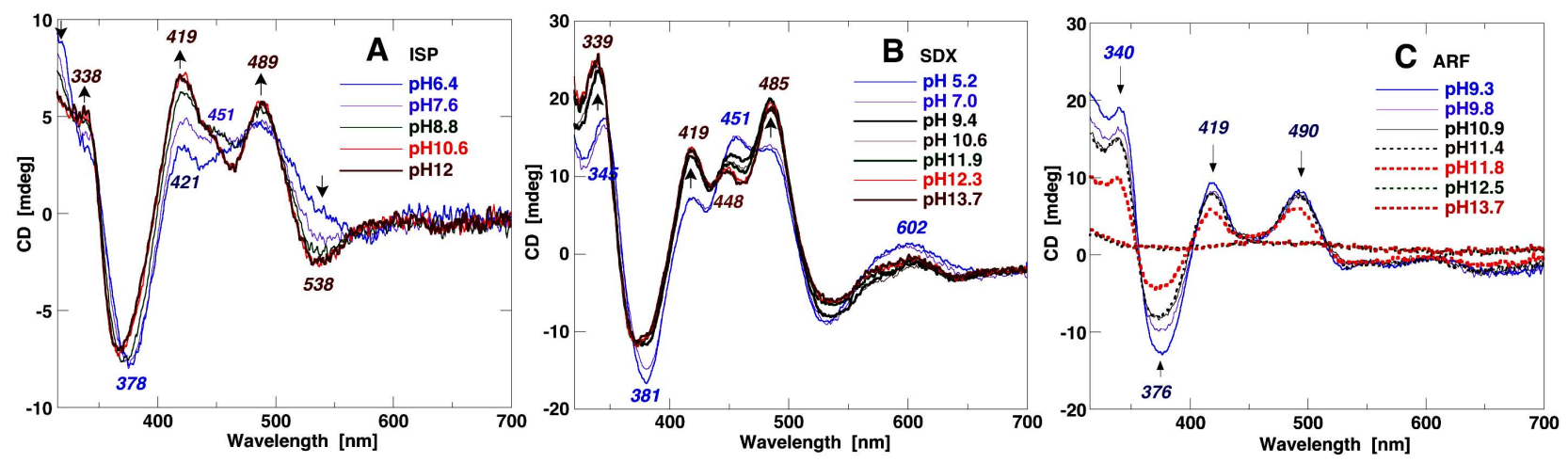

Figure S-1. The pH-dependence of selected visible-near UV CD spectra of the bacterial high-potential ISP $\left(\mathrm{p} K_{a, o x 1,2}\right.$ of $7.6 \pm 0.1$ and $9.6 \pm 0.1$, respectively) ${ }^{6,7}(\mathbf{A})$, the archaeal high-potential SDX (pK $K_{a, o x l, 2}$ of $8.4 \pm 0.2$ and $\sim 12$, respectively) (B), and the archaeal low-potential ARF (C). The visible CD changes of ARF are different from those of ISP and SDX, and eventually lead to irreversible breakdown of the cluster due to alkaline denaturation (dashed lines in C). The spectra were recorded with a JASCO J720 spectropolarimeter with 0.1 or 0.5 -cm cells.

(1) Suzuki, T.; Iwasaki, T.; Uzawa, T.; Hara, K.; Nemoto, N.; Kon, T.; Ueki, T.; Yamagishi, A.; Oshima, T. Extremophiles 2002, 6, 39-44.

(2) (a) Cosper, N. J.; Eby, D. M.; Kounosu, A.; Kurosawa, N.; Neidle, E. L.; Kurtz, D. M. Jr.; Iwasaki, T.; Scott, R. A. Protein Sci. 2002, 11, 2969-2973. (b) Kounosu, A.; Li, Z.; Cosper, N. J.; Shokes, J. E.; Scott, R. A.; Imai, T.; Urushiyama, A.; Iwasaki, T. J. Biol. Chem. 2004, 279, in press.

(3) Iwasaki, T.; Kounosu, A.; Dikanov, S. A. In EPR in the $21^{\text {st }}$ Century; Kawamori, A., Yamauchi, J., Ohta, H., Eds.; Elsevier Science B.V.: Amsterdam, 2002, pp 488-493.

(4) Iwasaki, T.; Kounosu, A.; Aoshima, M.; Ohmori, D.; Imai, T.; Urushiyama, A.; Cosper, N. J.; Scott, R. A. J. Biol. Chem. 2002, 277, 39642-39648.

(5) Guergova-Kuras, M.; Salcedo-Hernandez, R.; Bechmann, G.; Kuras, R.; Gennis, R. B.; Crofts, A. R. Protein Expr. Purif. 1999, 15, 370-380.

(6) Guergova-Kuras, M.; Kuras, R.; Ugulava, N.; Hadad, I.; Crofts, A. R. Biochemistry 2000, 39, 74367444 .

(7) Zu, Y.; Couture, M. M.-J.; Kolling, D. R. J.; Crofts, A. R.; Eltis, L. D.; Fee, J. A.; Hirst, J. Biochemistry 2003, 42, 12400-12408. 